\title{
Analyzing Indicators Affecting Commercial Property Value in Metro Station Accessible Area Using Walking Time Consumption: Case of Xi'an, China
}

\author{
Zhen Cao $\mathbb{D}^{\mathbb{D}},{ }^{1}$ Xingliang Liu $\mathbb{D}^{\mathbb{D}},{ }^{2}$ Bin Lei $\mathbb{D}^{1},{ }^{1}$ Changjiang Liu $\mathbb{D}^{1},{ }^{1}$ and Lizhu Jing $\mathbb{D}^{3}$ \\ ${ }^{1}$ School of Civil Engineering, Xi'an University of Architecture and Technology, Xi'an 710055, China \\ ${ }^{2}$ College of Traffic and Transportation, Chongqing Jiaotong University, Chongqing 400074, China \\ ${ }^{3}$ Key Laboratory for Special Area Highway Engineering, Chang'an University, Xi'an 710064, China
}

Correspondence should be addressed to Xingliang Liu; xingliang1125@outlook.com

Received 15 March 2020; Revised 20 October 2020; Accepted 29 October 2020; Published 18 November 2020

Academic Editor: Rongqing Zhang

Copyright (c) 2020 Zhen Cao et al. This is an open access article distributed under the Creative Commons Attribution License, which permits unrestricted use, distribution, and reproduction in any medium, provided the original work is properly cited.

In studies investigating the property value enhancements along metro lines, study ranges in most cases are measured in Euclidean distance. However, city roads are not always straight, and Euclidean distance sometimes does not equal to actual distance the passenger travels from the public transport station to their home or a commercial spot. To solve this problem, this study analyzed the indicators affecting commercial property value in metro station accessible area in Xi'an, using walking time consumption in measuring the study range. Following a conceptual framework, considering empirical evidences in related studies, information in city structure, and metro distribution, the initial indicator set is built. Using hedonic price model (HPM), spatial autoregressive model (SAR), and error term (SEM), significant indicators affecting commercial property value are investigated. In this study, 14 significant indicators are determined and quantified. Threshold distance equals to $900 \mathrm{~m}$ is found to be appropriate in addressing the autocorrelation problem with the weighted decision matrix tool. Compared to HPM and SEM, SAR is found to perform the best in evaluating the significant indicators with the largest $R^{2}(0.415)$ and the lowest Akaike Info Criterion (AIC) (-395.214). Besides, it is discovered that the value of the commercial property lies in the study range of 20 min walking time and is obviously influenced by the metro station. The results discovered in this study could provide some empirical evidences to commercial property planning in Xi'an.

\section{Introduction}

In the formation process of a city, labor investment of the citizens bring value attributes to urban lands and properties, which are represented by selling or rental prices of residential and commercial properties in contemporary society [1]. Increases in accessibility to specific locations brought by urban public transports, especially metro system, will lead to trade improvements, employment density increases, and sometimes enhancement in land and property values [2-5]. To better understand the mechanism behind urban land value enhancements, this study focuses on determining indicators affecting the commercial property value in metro station accessible area, providing more empirical evidences to urban public transport planning and land development.
Many studies have investigated the value enhancements of urban lands along metro lines, including residential properties in Seoul [6], Chicago [7], Houston [8], and London [9] and commercial properties in Dallas and Denver [10], San Diego [11], Minneapolis [12], and Dubai [13]. Indicators affecting the property value discussed in these research studies are appropriately attributed into 12 dimensions in 2 categories [14], commercial property attractiveness ones and transit-oriented development (TOD) related ones, which could be regarded as a basis in building the initial indicator set in this study. This basis will be further elucidated in Section 3. However, study ranges considering passengers' accessibility in most of these research studies were measured in Euclidean distance. As the roads are not straight in most cases, Euclidean distance does not equal to 
actual distance the passenger travels from the public transport station to their home or a commercial spot. Therefore, in analyzing indicators affecting the commercial property value along metro lines, setting study range according to passengers' actual travel distances is needed, which will promote the practicality and credibility of the results. In this research, passengers' actual travel distance is measured in terms of walking time consumption.

To achieve the research objective, metro lines in Xi'an, China are selected as the research case. With this case, basic information including metro system distribution, metro passenger volume, and city subcenters are provided. The concept of walking time consumption is introduced in the study range using the example of a specific station in metro line 2. Based on the above listed contents, following the conceptual framework presented by Abutaleb et al. [14] and considering the 12 indicator dimensions referred in the second paragraph of this section, the initial indicator set depicting the attractiveness of a certain commercial property is built, and 422 commercial property samples are investigated. To simplify the initial indicator set, the hedonic price model (HPM) is used to eliminate the insignificant indicators. The autocorrelation problem in commercial property samples is solved using the threshold distance and the weighted decision matrix tool. After the comparison among the spatial autoregressive model (SAR), spatial autoregressive model in error term (SEM), and HPM, significant indicators affecting the commercial property value in metro station accessible areas are determined and quantified using $20 \mathrm{~min}$ walking time consumption, SAR, and $900 \mathrm{~m}$ threshold distance.

\section{Literature Review}

Majority related studies investigated the impact of the metro system on residential property value in a specific city. For instance, there have been studies on the metropolitan areas around the Seoul subway in South Korea [6], the Chicago rapid transit [7], Houston urban rail [8], and New Jersey light rail [15] in the USA, the London metro in the UK [9], the Montreal commuter train in Canada [16], the Dubai metro in the UAE [13], the Poznan Rapid Tram in Poland [17], and the Beijing Subway [18], Great Taipei Mass rapid transit [19], Tianjin Subway [20], and Shanghai subway [21] in China, etc. With the rise of TOD strategies, studies focused on the relationship between the metro system and commercial property value were carried out, following the residential properties ones. However, compared to residential property related studies, research on the commercial property value are in the minor part. Research studies in this area also use a certain city or area as a case. There have been studies on the metropolitan areas around the Dallas and Denver urban rail transit systems [10], the Santa Clara County light rail transit [22], the San Diego rail lines [11], and the Minneapolis light rail system [12] in the USA, the Seoul metro system in South Korea [23], the Manila metro lines in Philippines [24], and the Dubai metro in the UAE [13], etc. Based on the findings reported in abovementioned studies, there are two problems to be appropriately solved in analyzing the indicators affecting commercial property value in metro station accessible area. (1) A comprehensive initial indicator set considering structure, time, location, local context, etc., should be built as the basis of the research $[21,25,26]$. (2) Suitable methods should be chosen to handle the tasks of quantifying the significance of indicators, eliminating the insignificant indicators, and solving autocorrelation problems [27].

To the first problem, the above listed studies [6-24] provided the initial indicator set using traditional literature review techniques, which were basically subjective explanations of results obtained from different city cases, and the systematic analysis of indicators ever mentioned was rarely conducted. Debrezion et al. [28] developed a relatively large initial indicator set based on a meta-analysis model. In this study, indicators in property type, public transport system type, empirical model type, analysis time period, roads accessibility, etc., were included. To our best knowledge, this is a study trying to consider every indicator which might have potential impact on the commercial or residential property value. However, to be exhaustive in building the initial indicator set is not necessary. Because most indicators affecting property values are closely connected with local economic and geographic conditions, etc., and indicators involved in a study on one city will be different from the study on another [27]. Therefore, if generic indicator selection guidance could be found, the problem of building initial indicator set could be solved in an easier and proper way. In a recent study conducted by Abutaleb et al. [14] a conceptual framework for evaluating the indicators related to rail transit-oriented commercial property development was established. All the indicators involved were divided into two categories, commercial property attractiveness ones and TOD-related ones, and they were further attributed into 12 dimensions, as referred in Section 1. In this way, this framework clearly detailed the inner logic behind the indicators might potentially affect the commercial property value in metro accessible areas. Thus, this conceptual framework could act as the guidance in solving the first problem, scilicet, building the initial indicator set in this study.

To the second problem, quantifying the significance of indicators could be handled using difference-in-differences (DiD) approach, HPM, and spatial econometric models including SAR and SEM. As reported in related study [29], the core of DiD approach is a comparison of a before-after (the settlement of metro lines or stations) estimate of property values between properties in metro accessible area and comparable properties outside this area. Therefore, DiD approach is basically used in analyzing property value variation in a certain time period (several years) [30]. To this study, the indicators affecting commercial property value along metro lines are evaluated considering passengers' walking distances, which is a spatial problem. HPM, SAR, and SEM perform more suitable than DiD approach in dealing spatial problems $[27,31]$. As the initial indicator set usually includes all the possible indicators having potential impact on the commercial property value, redundant indicators should be eliminated at the first step [21, 25, 27]. 
This issue is usually fixed by using HPM, owing to its convenience in providing quantified significances to all the indicators [27]. However, autocorrelation problem has often been reported with the use of the HPM [31]. To address this problem, SAR and SEM have been adopted. In related studies [32, 33], SAR and SEM were proved to be efficient in dealing autocorrelation problem, but evidence showing which approach performs better was not found. In that, this study will eliminate the redundant indicators using HPM at first. Then, the indicators affecting the commercial property value in metro station accessible area will be determined based on a comparison among HPM, SAR, and SEM.

\section{The Research Design}

3.1. Study Area. Study case selection mainly takes aspects of economic, geographic, and transportation conditions into consideration [27]. The GDP of Xi'an ranked 24 among 343 China mainland cities in 2019 (932.1 billion RMB), and both GDP and its growth rate $(7.0 \%$ in $2019,8.2 \%$ in 2018 , and $19.4 \%$ in 2017) have been in the top position for several years among China northwest cities. In geographic and transportation aspects, Xi'an just locates in the north-south, also the east-west boundary of China. Therefore, it is one of the most important transportation hubs in China, intersected by several transportation arterials, for instances, ZhengzhouXi'an, Baoji-Xi'an, Datong-Xi'an, and Chengdu-Xi'an highspeed railways. Overviewing abovementioned backgrounds, Xi'an is appropriate to be a research case. Moreover, evidences related to indicators affecting the property value along metro lines in China northern city (Tianjin [20]), eastern city (Shanghai [21]), and southern city (Wuhan [27]) could be found. Empirical findings in northwest city may help in forming a comprehensive $s$ on property value research in China.

Currently, Xi'an has four metro lines in operation, known as Metro Line (ML) \#1-4, as shown in Figure 1. ML \#2 was first opened to the public in 2011, owning the highest passenger flow with more than 1.2 million per day (data from April 2019), and it passes three subcenters, Government Center, Inner Wall Area and Yanta-Qujiang Area. ML \#1, opened in 2013, passes only one subcenter (Inner Wall Area). It also has significant passenger flow, which is more than 0.76 million per day (data from May 2019). ML \#3 and ML \#4 opened in November 2016 and December 2018, respectively. ML \#4 passes the same subcenters as ML \#2. However, its passenger flow is lower, about 0.4 million per day (data from March 2019). ML \#3 passes two subcenters, Yanta-Qujiang Area and Gaoxin Business Area. Its passenger flow is about 0.5 million per day (data from April 2019). As ML \#3 and ML \#4 began their service more recently and their ridership is still increasing, their impact on surrounding commercial property value is still not stable. Moreover, only data from 2019 is available for ML \#3 and ML \#4. Therefore, in this study, ML \#1 and ML \#2 are selected as the study focus. Additionally, as the ridership of ML \#1 reached stability after 2015, the data related to commercial properties along ML \#1 and ML \#2 in 2015 to 2018 will be used in this study.

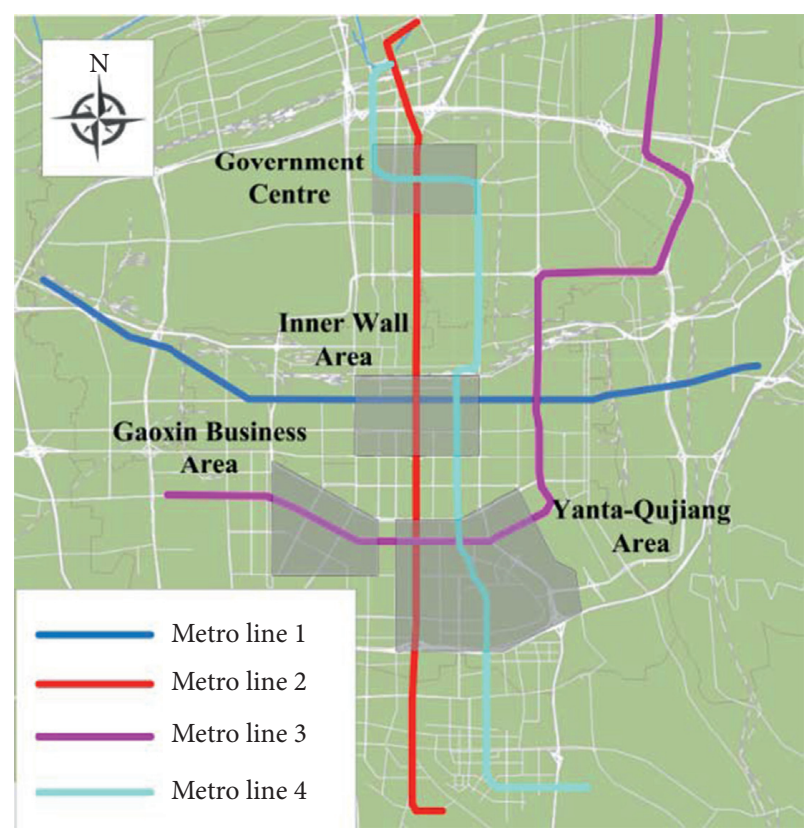

Figure 1: Deployment of the urban rail transit system in Xi'an.

3.2. Study Range Based on Walking Time Consumption. The distance between a specific metro station and commercial properties in and around the station is the main factor that is considered when analyzing indicators affecting the commercial property value along metro lines $[5,16,27,34]$. This distance is the study range that is discussed in this section. If a commercial property does not lie within the study range, the accessibility of the metro lines has no impact on its commercial property value. In related studies, the study range was measured using Euclidean distance $[5,27,34]$, which means that the study range is a circle centered on a certain station with a specific radius. However, as introduced in Section 1, Euclidean distance does not equal to actual distance the passenger travels from the metro station to a commercial spot as the roads are not straight in most cases. The study range measurement method representing passengers' actual travel distances is needed.

To choose an appropriate method considering passengers' actual travel distances in measuring the study range, the characteristics of the local road network should be considered. Figure 2 shows the detailed road network around Zhonglou Station on ML\#2. In this figure, based on the Euclidean distance, the three blue points are all $500 \mathrm{~m}$ away from the station, and the red arrows depict the walking routes taken to go from the station to these points. Route 1 uses an arterial road, and its walking distance is $500 \mathrm{~m}$, which would require about six minutes based on a walking speed of $5 \mathrm{~km} / \mathrm{h}$ [35]. Route 2 uses parts of two alleys and an arterial. Its walking distance is also $500 \mathrm{~m}$ and would require about six minutes to travel. There are similar distance and time requirements for these two routes because the alleys are directly connected to the arterial road and the road sections are perpendicular to each other. However, route 3 is different. Passengers walking to the station must first detour 


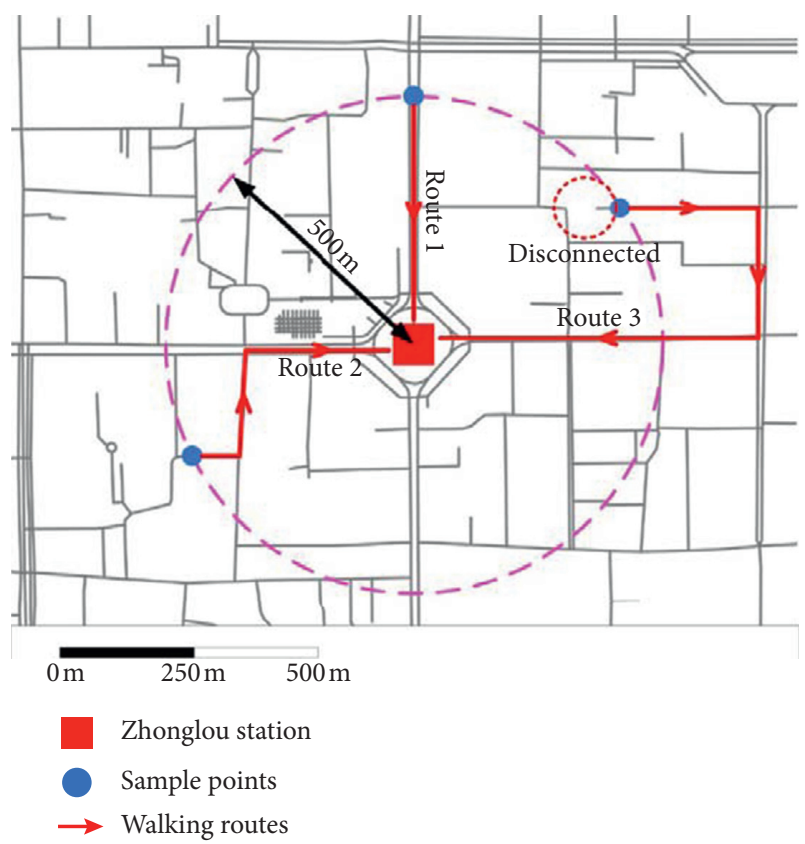

Figure 2: Map of the road network around Zhonglou Station on ML \#2 showing three different routes that can be taken to arrive at points that would be considered equidistant from the station based on the Euclidean distance.

eastward due to the disconnected section, which is depicted in Figure 2. Thus, the walking distance of route 3 is $1100 \mathrm{~m}$, and 13 minutes is required to travel this route. From this example, it is clear that the study range measurement depends on the connectivity and grid shape of the road network. In cities with a highly connected checkerboard-like road network, the Euclidean distance is an efficient method of measuring the study range. However, in Xi'an, there is relatively low connectivity in the road network due to the constant conflict between urban construction and the protection of ancient buildings. Therefore, phenomenon such as route 3 is common in Xi'an. Thus, the study range measurement using walking time is adopted in this article.

Moreover, when measuring the walking distance, a diverse group of passengers should be considered because of the different walking speeds of teenagers, young children, and the elderly. Based on data from the Xi'an 2019 Annual Travel Report [35], the majority of passengers were in the age groups of $18-40$ and $41-60$, and they constituted $33.2 \%$ and $45.7 \%$ of all the passengers, respectively. The report also provided the average walking speed of each age group, which were $4.9 \mathrm{~km} / \mathrm{h}$ and $5.1 \mathrm{~km} / \mathrm{h}$, respectively. Thus, the average of the two, $5.0 \mathrm{~km} / \mathrm{h}$, was taken as the passengers' walking speed.

Figure 3 provides a map around Zhonglou Station on ML \#2 that shows the study range based on walking distance. The red square indicates the position of Zhonglou Station, and the study range is represented by irregularly shaped colored areas. For instance, the boundary of the innermost white-colored area represents a walking distances that would take up to five minutes to reach. This means that traveling from Zhonglou Station to any point within the inner white region would require up to 5 minutes, based on optimal route selection. Colored area in Figure 3 represents a study range in which the walking distance will be less than $25 \mathrm{~min}$, and commercial properties that lie within this range will be affected by Zhonglou Station on ML \#2. To guarantee a sufficiently large sample number, walking distances that require up to 40 minutes to travel are considered in this study.

\subsection{Methodology}

3.3.1. Initial Indicator Set. As mentioned in Section 2, the conceptual framework presented by Abutaleb et al. [14] is used as guidance in building the initial indicator set in this study. In this framework, all the indicators were divided into two categories, the commercial property attractiveness ones, which were further divided into seven dimensions, as shown in Table 1, and TOD-related ones that were divided into five dimensions, as shown in Table 2.

The first step of the building initial indicator set is determining the dependent variable. In related studies $[10-12,22-24,27]$, the selling or rental price of commercial properties was used as the dependent variable. Based on market research (http://www.sofang.com), $82.3 \%$ of commercial properties in Xi'an are leased. Therefore, the rental price in RMB Yuan per $\mathrm{m}^{2}$ per month is used as the dependent variable in this research.

Taking the framework by Abutaleb et al. [14] and other related studies [21, 25-27] into consideration, the indicators that have shown significant impact on the commercial property value are selected. Among the indicators in Table 1, types, business duration, construction area, location, and reputation are recognized as effective. Among the indicators in Table 2, shops areas, services areas, facilities areas, scenic areas, recreational areas, parking space, links, and transit proximity are identified as effective.

Following the guidance provided above, there still remains a problem, the definitions of some indicators are still not clear, which could be further classified. Second, some indicators have been proven to be insignificant. To the first problem, according to existing evidences [12-14, 27], "Types" could be further split into "Shopping Mall," "Commercial Street," and "Roadside Retail," "Location" could be subdivided into "Distance to Subcenter" and "Distance to Metro station," "Transit Proximity" could be subdivided into "Bus Line Number" and "Urban Center Bus," and "Diversity" could be specifically represented by "Plaza," "Office," "School," "Hospital," and "Leisure Spot." Combining the urban structure in Xi'an and some empirical results [27], subcenters in Xi'an should be involved. Thus, "Government Center," "Inner Wall Area," "Yanta-Qujiang Area," and "Gaoxin Business Area" introduced in Section 3.1 should be considered. Moreover, as the rental price was chosen as the dependent variable in this research, the "Rent Time" indicator should be included [27].

Despite the fact that "commercial property value is related to the ridership of the nearest metro station" [14], 


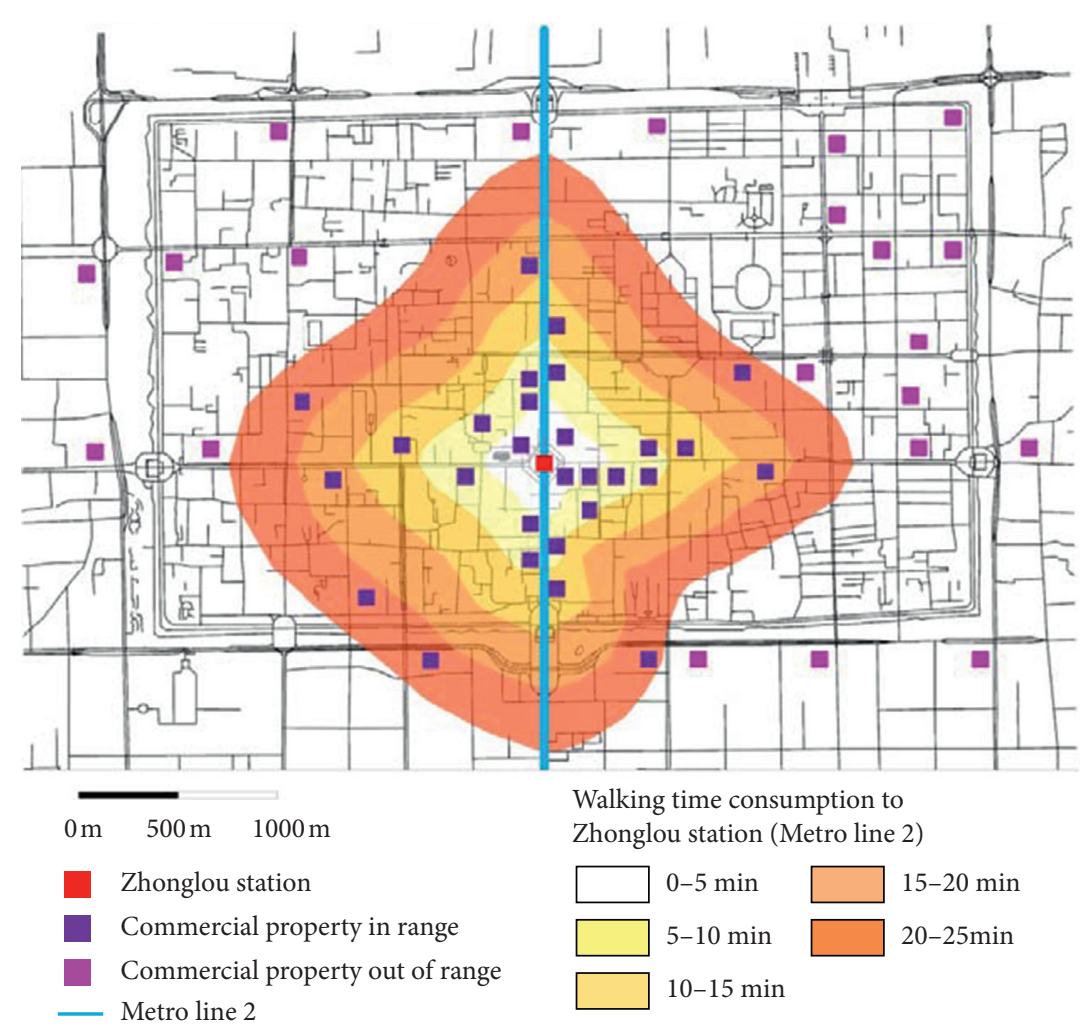

FIgURE 3: Explanation of the study range based on walking distance, using the example of Zhonglou Station on ML \#2.

TABLE 1: Overview in commercial property attractiveness-related indicators [14].

\begin{tabular}{lc}
\hline Dimensions & Indicator included \\
\hline Product & Types, quality, variability, availability, provision, activities, and business duration \\
Price & Discounts and payment options \\
Place & Construction area, facilities, and location \\
Promotion & Promotional campaigns and advertisement \\
People & Staff helpfulness and crowdedness \\
Physical evidence & Environment, reputation \\
Process & Search process and service process \\
\hline
\end{tabular}

Detailed definition of each indicator could be found in [14].

TABLE 2: Overview in TOD-related indicators [14].

\begin{tabular}{lc}
\hline Dimensions & Indicators included \\
\hline Density & Business establishments, built-up area, floor area, and population \\
Diversity & Shops areas, services areas, facilities areas, scenic areas, and recreational areas \\
Urban design & Walkways, parking space, and links \\
Destination accessibility & Parking space and transit proximity \\
Distance & Transit proximity and rail and bus stations \\
\hline
\end{tabular}

Detailed definition of each indicator can be found in [14].

indicators related to the metro station are ignored in traditional studies [21, 25-27]. Therefore, the three indicators, "Passenger Flow," "Duration," and "Transfer Station," which would have impact on the metro station ridership [35], are also included in this study. All the indicators listed in the initial set must be quantified to be used in the HPM, SAR, and SEM mentioned in Section 1. Thus, based on existing evidences $[12-14,21,25-27,35]$, each indicator in the initial set is defined and its possible quantitative values are presented in Table 3. All the initial indicators are appropriately quantified, most of which are binary variables [12, 27]. Additionally, the radius of $800 \mathrm{~m}$ around the commercial property is selected based on empirical evidence found in the related study [27]. 
TABLE 3: Initial indicator set: definitions and quantification methods.

\begin{tabular}{|c|c|}
\hline Indicators & Definitions and quantification methods \\
\hline Shopping mall & Whether the property is a shopping mall $(\mathrm{yes}=1, \mathrm{no}=0$ ) \\
\hline Commercial street & Whether the property is on a commercial street $(1,0)$ \\
\hline Roadside retail & Whether the property is a roadside retail $(1,0)$ \\
\hline Link & Whether the property is directly connected to a metro station $(1,0)$ \\
\hline Construction area & Total construction area of the commercial property $\left(\mathrm{m}^{2}\right)$ \\
\hline Business duration & Time period since it was opened to public (years) \\
\hline Reputation & Reputation of the commercial property $($ famous $=1$, not known $=0$ ) \\
\hline Parking space & Number of parking spaces \\
\hline Rent time & The year that the current owner began renting the property \\
\hline Distance to sub center & Distance to nearest subcenter $(\mathrm{km})$ \\
\hline Distance to metro station & Walking distance to nearest metro station ( $\mathrm{min})$ \\
\hline Government center & Whether the property is located in the Government Center $(1,0)$ \\
\hline Inner wall area & Whether the property is located in the Inner Wall Area $(1,0)$ \\
\hline Yanta-Qujiang area & Whether the property is located in the Yanta-Qujiang Area $(1,0)$ \\
\hline Gaoxin business area & Whether the property is located in the Gaoxin Business Area $(1,0)$ \\
\hline Bus line number & Number of bus routes within $800 \mathrm{~m}$ \\
\hline Urban center bus & Number of bus routes passing an urban center within $800 \mathrm{~m}$ around \\
\hline Plaza & Within $800 \mathrm{~m}$ of the plaza $(0,1)$ \\
\hline Office & Within $800 \mathrm{~m}$ of the Office $(0,1)$ \\
\hline School & Within $800 \mathrm{~m}$ of the school $(0,1)$ \\
\hline Hospital & Within $800 \mathrm{~m}$ of the hospital $(0,1)$ \\
\hline Leisure spot & Within $800 \mathrm{~m}$ of the leisure spot $(0,1)$ \\
\hline Passenger flow & Nearest metro station's daily passenger flow (thousand/day) \\
\hline Duration & When the nearest metro station opened (year) \\
\hline Transfer station & Whether the nearest metro station is a transfer station $(0,1)$ \\
\hline
\end{tabular}

To analyze the significance of listed indicators affecting the commercial property value along metro lines, large amounts of empirical data are needed. In this research, 21 metro stations on ML \#1 and ML \#2 in Xi'an downtown areas and the commercial properties within a certain range around each station were investigated. Empirical data were collected in August 2019, and only commercial properties of shopping mall, commercial street, and roadside retail in the predefined study range $(40 \mathrm{~min}$ walking time consumption) introduced in Section 3.2 were investigated. Besides, the amount of roadside retails is huge. To balance the volume of listed three commercial property types, roadside retail sample number around each station was controlled no more than 10 . The roadside retail samples should also be evenly distributed around the station [27]. Both field and Internet investigations were utilized to collect the necessary data. The operators of commercial properties within the study range were interviewed to determine the values of the "Shopping Mall," "Commercial Street," "Roadside Retail," "Link," "Construction Area," "Business Duration," "Parking Space," and "Rent Time" indicators and the dependent variable "rental price." To gather information regarding the "Reputation" indicator, customers were randomly interviewed. In a commercial property, certain volume customers (about 100 in shopping mall and commercial street and 20 in roadside retail) were interviewed. They were asked to answer a question "is this the first time you visit this commercial spot." If the answer of majority interviewees is "no," this commercial property would be regarded as a famous one, on the contrary, a not known property. For the indicators from "Distance" to "Leisure Spot" in Table 3, the online system called "Gaode Map" (https://www. amap.com/) was used. Moreover, the metro operation company was contacted for information on the "Passenger Flow," "Duration," and "Transfer Station" indicators. Finally, data regarding 422 commercial property samples within a 40 minute walking distance of Xi'an's ML \#1 and ML \#2 were obtained, and the statistical results are provided in Table 4.

3.3.2. Hedonic Price Model. As discussed in Section 2, the commercial property value, which is represented by its selling or rental price, is affected by a series of indicators. To quantitatively study the relationship between commercial property value and metro station accessibility, HPM has been used in several related studies [21, 25, 27] based on multiple linear regression (MLR). MLR estimates the potential value of a specific attribute for a certain commodity by using the ordinary least-squares (OLS) estimator. When using this method, the selling or rental price of the commercial property was treated as a dependent variable, and quantitative urban rail transit related attributes, such as the distance to the transit station, geographic location, and neighborhood type, were treated as explanatory variables. Generally, HPM has three basic forms, which are the linear, $\log -\log$, and semilog forms, and they are illustrated as

$$
\begin{gathered}
p_{i}=\alpha_{0}+\sum_{k=1}^{m} \alpha_{k} \chi_{k i}+\varepsilon_{i} \\
\ln p_{i}=\alpha_{0}+\sum_{k=1}^{m} \alpha_{k} \ln \chi_{k i}+\varepsilon_{i} \\
\ln p_{i}=\alpha_{0}+\sum_{k=1}^{m} \alpha_{k} \chi_{k i}+\varepsilon_{i} .
\end{gathered}
$$


TABLE 4: Statistical results of the commercial property samples along Xi'an's ML \#1 and ML \#2.

\begin{tabular}{lcccc}
\hline Indicators & Number & Min. & Max. & St. Dev. \\
\hline Shopping mall & 422 & 0 & 1 & 0.27 \\
Commercial street & 422 & 0 & 1 & 0.33 \\
Roadside retail & 422 & 0 & 1 & 0.51 \\
Link & 422 & 0 & 1 & 0.11 \\
Construction area & 422 & 7 & 250000 & 9127.33 \\
Business duration & 422 & 0.1 & 21 & 5.23 \\
Reputation & 422 & 0 & 1 & 0.21 \\
Parking space & 422 & 0 & 1630 & 43.31 \\
Rent time & 422 & 2015 & 2018 & 0.33 \\
Distance to subcenter & 422 & 0 & 5.5 & 0.93 \\
Distance to metro station & 422 & 0 & 28 & 7.22 \\
Government center & 422 & 0 & 1 & 0.11 \\
Inner wall area & 422 & 0 & 1 & 0.32 \\
Yanta-Qujiang area & 422 & 0 & 1 & 0.57 \\
Gaoxin business area & 422 & 0 & 1 & 0.18 \\
Bus line number & 422 & 3 & 22 & 6.28 \\
Urban center bus & 422 & 0 & 17 & 2.77 \\
Plaza & 422 & 0 & 1 & 0.13 \\
Office & 422 & 0 & 1 & 0.27 \\
School & 422 & 0 & 1 & 0.56 \\
Hospital & 422 & 0 & 1 & 0.45 \\
Leisure spot & 422 & 0 & 1 & 0.41 \\
Passenger flow & 422 & 39.2 & 245.9 & 51.2 \\
Duration & 422 & 6 & 8 & 1.76 \\
Transfer station & 422 & 0 & 1 & 0.19 \\
\hline Rental price & 422 & 421 & 1540 & 835.16 \\
N & 422 & & & \\
\hline
\end{tabular}

In these equations, $p_{i}$ is the selling or rental price of the $i$ th commercial property unit in yuan $/ \mathrm{m}^{2}, \chi_{k i}$ is the value of the $k$ th attribute of the $i$ th commercial property unit, $\varepsilon_{i}$ is a random error term, and $\alpha_{0}$ and $\alpha_{k}$ are parameters that need to be estimated. There has been no evidence that any of the HPM forms provides an advantage over the others $[21,25,27]$. In selecting the basic form of the model, two aspects should be considered, which are the sample characteristics and estimation performance. In related study [27], the semilog form of HPM showed an obvious superiority in terms of statistical indicators. Thus, the semilog form of HPM is chosen in this research.

3.3.3. Spatial Economic Model. Some shortfalls of HPM have been discovered in related studies, which include problems related to nonrandom variables, choosing the proper modeling form, and autocorrelation in the collected data $[27,31]$. In commercial property related studies, spatial autocorrelation and heterogeneity problems derived from the unique location attributes of the real estate properties [36]. For instance, if a commercial property has a significant reputation and large pedestrian flow, the nearby shops will also have a relatively high selling or rental price. This is a natural phenomenon that is not affected by the urban rail transit observed in central business district (CBD). To find and solve the autocorrelation problem, the spatial economic model has been widely adopted $[26,32,33]$. In the spatial economic model, there are two basic forms that are typically used; SAR and SEM. In SAR, HPM is transformed by introducing a spatial autoregressive structure, which is shown in equation (2), while in SEM, HPM is transformed by adding a mathematical explanation, as shown in equation (3):

$$
\begin{gathered}
\ln p_{i}=\alpha_{0}+\rho W \lg p_{i}+\sum_{k=1}^{m} \alpha_{k} \chi_{k i}+\varepsilon_{i}, \\
\left\{\ln p_{i}=\alpha_{0}+\sum_{k=1}^{m} \alpha_{k} \chi_{k i}+\varepsilon_{i}, \varepsilon_{i}=\lambda W \varepsilon_{i}+\mu .\right.
\end{gathered}
$$

In the above equations, $\rho$ and $\lambda$ are the spatial autoregressive coefficients of errors and $W$ is the spatial weight matrix, which represents the interaction between spatial observations that could influence the significance of the test procedures [27, 37]. Thus, the spatial weight matrix $W$ plays a key role in the SAR and SEM models. There are three ways to obtain a proper spatial weight matrix, which are contiguity, fixed number of neighbors, and distance threshold [32]. The distance threshold method was used in the Wuhan case, and it has been proven to be efficient in spatial dependence analysis [27]. Therefore, this method is also adopted in this study.

\section{Results}

4.1. Elimination of Insignificant Variables. Following HPM introduced in Section 3.3.2, significance of each indicator, also quantified relationship between the indicator and rental price are obtained, is shown in Table 5. The parameter "Coef." indicates the strength of the relationship between the indicator and dependent rental price variable, where a stronger association exists for larger absolute values of "Coef." and the "+/-" sign indicates a positive/negative correlation. The "Sig." parameter is used to judge whether the indicator is significant or insignificant. Any indicator with a "Sig." value larger than 0.1 is regarded as insignificant and further eliminated [27]. The "variance inflation factor (VIF)" is used to test the indicator's independence. The indicator with a much larger VIF value suggests that the indicator is intercorrelated with other indicators and should be merged with other indicators that have similar effects on rental price [27]. This is a phenomenon known as multicollinearity [36].

To eliminate insignificant indicators, HPM are usually used for several times [27]. In each time, indicator's "Sig." value varies, and the one varies to larger than 0.1 is excluded. When there is no "Sig." value larger than 0.1 and "Coef." value remains stable, also no much larger "VIF" observed, the process should stop, and leftover indicators are regarded as the significant ones. According to the result, 14 indicators are found to be significant. In the first HPM results, none of the indicators has a much larger "VIF," proving that all the initial indicators selected are independent from one another. Considering empirical evidences found in Wuhan [27], Queensland [38], Seoul [23], and Athens [39], multicollinearity in initial indicator set was reported. It is not observed in this research because indicators with similar 
TABLE 5: Estimated variables using HPM models.

\begin{tabular}{lcccc}
\hline \multirow{2}{*}{ Indicators } & \multicolumn{2}{c}{1 st HPM } & \multicolumn{2}{c}{$2^{\text {nd }}$ HPM } \\
& Coef. & VIF & Coef. & VIF \\
\hline Shopping mall & $0.032^{* *}$ & 1.285 & $0.034^{* *}$ & 1.854 \\
Commercial street & $0.019^{* *}$ & 1.564 & $0.020^{* *}$ & 1.219 \\
Roadside retail & -0.005 & 2.054 & - & - \\
Link & $0.017^{*}$ & 1.597 & $0.018^{* *}$ & 1.548 \\
Construction area & $0.037^{* *}$ & 2.256 & $0.039^{* *}$ & 1.637 \\
Business duration & 0.000 & 1.125 & - & - \\
Reputation & $0.120^{* *}$ & 1.715 & $0.122^{* *}$ & 1.854 \\
Parking space & $0.009^{*}$ & 1.522 & $0.009^{* *}$ & 1.247 \\
Rent time & -0.021 & 2.657 & - & - \\
Distance to subcenter & -0.006 & 3.021 & - & - \\
Distance to metro station & $-0.211^{* * *}$ & 1.599 & $0.219^{* *}$ & 1.177 \\
Government center & 0.041 & 1.564 & - & - \\
Inner wall area & $0.355^{* *}$ & 2.014 & $0.355^{* *}$ & 1.546 \\
Yanta-Qujiang area & $0.420^{* *}$ & 1.954 & $0.421^{* *}$ & 2.012 \\
Gaoxin business area & $0.030^{*}$ & 1.025 & $0.030^{* *}$ & 1.578 \\
Bus line number & $0.018^{*}$ & 1.296 & $0.019^{* *}$ & 1.695 \\
Urban center bus & 0.005 & 1.322 & - & - \\
Plaza & 0.007 & 2.895 & - & - \\
Office & 0.010 & 3.033 & - & - \\
School & $0.012^{*}$ & 1.784 & $0.014^{* *}$ & 1.569 \\
Hospital & $-0.095^{*}$ & 1.564 & $-0.100^{* *}$ & 1.284 \\
Leisure spot & 0.009 & 1.458 & - & - \\
Passenger flow & $0.253^{* *}$ & 2.597 & $0.255^{* *}$ & 1.144 \\
Duration & 0.002 & 1.125 & - & - \\
Transfer station & 0.097 & 1.458 & - & - \\
$R^{2}$ & 0.411 & - & 0.402 & - \\
$N$ & 422 & - & 422 & - \\
\hline & & & &
\end{tabular}

${ }^{* *}$ Sig $<0.05$ and ${ }^{*}$ Sig $<0.10$.

effects on the rental price were intentionally merged when building the initial indicator set with the guidance of Abutaleb et al. [14] and meaningful results from other related studies [12, 13, 21, 23, 25-27].

\subsection{Autocorrelation Avoidance and Model Selection.} Autocorrelation problem is reported in Section 2, and as described in Section 3.3.3, it could be solved by using the weighted decision matrix tool $W$. The threshold distance is adopted to build this weighted matrix. The threshold distance can be interpreted as a boundary spatial distance between two commercial properties. If the actual distance between two commercial properties is less than the threshold distance, the effect of spatial dependence would be significant. Thus, to determine the threshold distance, $650 \mathrm{~m}$, $800 \mathrm{~m}, 900 \mathrm{~m}, 1000 \mathrm{~m}, 1100 \mathrm{~m}, \ldots, 1500 \mathrm{~m}$ are used as test values. At a threshold distance of $650 \mathrm{~m}$, each commercial property is guaranteed to have at least one neighbor, and spatial dependence would be meaningful in this case. As shown in Table 6, nine matrixes are built, and Moran's Index (MI), the Lagrange Multiplier Test (LM), and the Robust Lagrange Multiplier Test (RLM) are used to determine the appropriate threshold distance $[23,27]$. Maximum values of MI and LM are achieved at $900 \mathrm{~m}$, while the RLM decreases with increasing threshold distance. Considering the trends of MI, LM, and RLM, $900 \mathrm{~m}$ is determined to be the appropriate threshold distance. Considering the threshold
TABLE 6: Autocorrelation tests based on spatial weight matrices.

\begin{tabular}{lccc}
\hline Threshold distance & MI & LM & RLM \\
\hline $650 \mathrm{~m}$ & $3.905^{* *}$ & $26.185^{* *}$ & $23.754^{* *}$ \\
$800 \mathrm{~m}$ & $4.233^{* *}$ & $29.332^{* *}$ & $21.584^{* *}$ \\
$900 \mathrm{~m}$ & $5.721^{* *}$ & $31.271^{* *}$ & $19.547^{* *}$ \\
$1000 \mathrm{~m}$ & $5.234^{* *}$ & $26.052^{* *}$ & $17.248^{* *}$ \\
$1100 \mathrm{~m}$ & $4.858^{* *}$ & $21.331^{* *}$ & $15.254^{* *}$ \\
$1200 \mathrm{~m}$ & $4.572^{* *}$ & $18.027^{* *}$ & $13.258^{* *}$ \\
$1300 \mathrm{~m}$ & $4.219^{* *}$ & $15.225^{* *}$ & $10.274^{*}$ \\
$1400 \mathrm{~m}$ & $4.011^{*}$ & $12.877^{*}$ & $6.551^{*}$ \\
$1500 \mathrm{~m}$ & $3.858^{*}$ & $8.552^{*}$ & 3.214 \\
\hline
\end{tabular}

${ }^{* *}$ Sig $<0.05$ and ${ }^{*} \operatorname{Sig}<0.10$.

distances reported in related studies, which were $0.5 \mathrm{~km}$ in Dubai [13], 1.85 miles in Dallas, 3.3 miles in Denver [10], $0.5 \mathrm{~km}$ in Seoul [23], and $1.0 \mathrm{~km}$ in Wuhan [27], there have been a wide range of threshold values used. The proper threshold distance depends on the characteristics of a specific city, and selecting this value using a weighted decision matrix tool is necessary.

The next task is to select a proper modeling method. An autocorrelation problem has been identified based on the previous analysis, and a threshold distance of $900 \mathrm{~m}$ is determined to be appropriate for Xi'an. SEM and SAR are efficient methods of solving this autocorrelation problem. However, the advantages of each method still need to be evaluated. Therefore, using the 14 significant variables selected in Table 5, we transformed the basic HPM to SEM and SAR, and the estimation results are shown in Table 7 . The coefficients in SAR and SEM show some differences to those in the basic HPM due to the transformation. The $R^{2}$ and Akaike Info Criterion (AIC) parameters are used to judge the model's performance [27], where larger $R^{2}$ and absolute AIC values indicates that the modeling results are more reliable. SAR has the largest $R^{2}(0.415)$, followed by SEM (0.411) and then the HPM (0.402). Moreover, the AIC also suggests that SAR provides the best performance (-395.214), followed by SEM (-355.610) and then HPM (-332.148). Therefore, it is concluded that SAR provides the best variables estimation for Xi'an. Related study [40] suggested that, with an appropriate threshold distance, the SAR model could perform better than the basic HPM and SEM; however, there is insufficient evidence to prove this at that time. However, with the results in this article and from other cases, including Seoul [23] and Wuhan [27], it is clear that SAR outperforms the basic HPM and SEM.

4.3. Indicator Estimation Using Walking Time Consumption. Using the simplified significant variables and the superior model method identified, the quantified analysis of the indicators affecting the commercial property value in metro station accessible areas is presented in this section. However, prior to this, a proper study range must be identified. As depicted in Section 3.2, the walking distance is represented by the time needed for a passenger to walk from the station to a surrounding commercial property, and this value is used to measure the study range in this study. We divided the walking distances into 8 subranges based on 5 -minute 
TABLE 7: Comparison of the HPM, SAR, and SEM models.

\begin{tabular}{lccc}
\hline Indicators & HPM coef. & SAR coef. & SEM coef. \\
\hline Shopping mall & $0.034^{* *}$ & $0.032^{* *}$ & $0.032^{* *}$ \\
Commercial street & $0.020^{* *}$ & $0.019^{* *}$ & $0.020^{* *}$ \\
Link & $0.018^{* *}$ & $0.021^{* *}$ & $0.020^{* *}$ \\
Construction area & $0.039^{* *}$ & $0.037^{* *}$ & $0.030^{* *}$ \\
Reputation & $0.122^{* *}$ & $0.131^{* *}$ & $0.095^{* *}$ \\
Parking space & $0.009^{* *}$ & $0.009^{* *}$ & $0.009^{* *}$ \\
Distance to metro station & $-0.219^{* *}$ & $-0.224^{* *}$ & $-0.226^{* *}$ \\
Inner wall area & $0.355^{* *}$ & $0.405^{* *}$ & $0.300^{* *}$ \\
Yanta-Qujiang area & $0.421^{* *}$ & $0.470^{* *}$ & $0.458^{* *}$ \\
Gaoxin business area & $0.030^{* *}$ & $0.015^{* *}$ & $0.017^{* *}$ \\
Bus line number & $0.019^{* *}$ & $0.024^{* *}$ & $0.021^{* *}$ \\
School & $0.014^{* *}$ & $0.015^{* *}$ & $0.003^{* *}$ \\
Hospital & $-0.100^{* *}$ & $-0.110^{* *}$ & $-0.110^{* *}$ \\
Passenger flow & $0.255^{* *}$ & $0.259^{* *}$ & $0.257^{* *}$ \\
$R^{2}$ & 0.402 & 0.415 & 0.411 \\
Akaike info criterion (AIC) & -332.148 & -395.214 & -355.610 \\
\hline
\end{tabular}

${ }^{* *}$ Sig $<0.05$ and ${ }^{*}$ Sig $<0.10$

intervals, from $0-5 \mathrm{~min}$ to $35-40 \mathrm{~min}$. The binary variables such as "Government Center" and "Inner Wall Area" are used to describe the location of the properties within the different subranges. Table 8 shows the results of the SAR model when the subranges are used instead of the "Distance to Metro station" indicator.

According to the "Sig." parameter shown in Table 8, when the study range exceeds 20 minutes, the impact of the urban rail transit became insignificant. Therefore, the proper study range is set to a 20-minute walking distance. In this case, with the proper study range, the final parameters estimation could be conducted using SAR and a 900-metre threshold distance. The results are shown in Table 9.

\section{Discussion}

The results in Table 9 provide a quantitative evaluation of each indicator. From these results, the impact of Xi'an's urban rail transit on value of commercial properties along the metro lines can be determined. The "Distance to Metro station" indicator directly reflects the association between urban rail transit access and commercial property value. As shown in Table 9, with increase in walking distance, the commercial property rental price decreases. This result is consistent with the findings in studies focused on Dubai [13], Dallas [10], Denver [10], San Diego [11], Minneapolis [12], Seoul [23], Manila [24], and Wuhan [27]. When the property lies within a $0-5 \mathrm{~min}$ walking distance, the rental price is $19.3 \%$ greater than the average rental price (1045 RMB Yuan per $\mathrm{m}^{2}$ ), and it is $18.8 \%, 14.1 \%$, and $10.8 \%$ greater than the average rental price for walking distances of 5-10, 10-15, and $15-20 \mathrm{~min}$, respectively. This trend is different from the one observed for residential properties. In studies focused on residential properties $[6-9,15,16]$, the property value mainly increases at first and then decreases, due to the noise or pollution caused by the urban rail transit. Furthermore, the "Passenger Flow" indicator is another element that laterally reflects the association between urban rail transit access and commercial property value. This indicator was
TABLE 8: Subrange estimation using the SAR model.

\begin{tabular}{lccc}
\hline Sub ranges & Coef. & Std. Error & $T$ \\
\hline Range of 0-5 min & $0.195^{* *}$ & 0.032 & 1.568 \\
Range of 5-10 min & $0.190^{* *}$ & 0.041 & 2.185 \\
Range of 10-15 min & $0.144^{* *}$ & 0.021 & 3.542 \\
Range of 15-20 min & $0.112^{*}$ & 0.015 & 1.258 \\
Range of 20-25 min & 0.065 & 0.038 & 2.547 \\
Range of 25-30 min & 0.070 & 0.027 & 0.695 \\
Range of 30-35 min & 0.058 & 0.045 & 1.242 \\
Range of 35-40 min & 0.023 & 0.029 & 2.216 \\
$R^{2}$ & 0.413 & - & - \\
AIC & -387.254 & - & - \\
\hline
\end{tabular}

${ }^{* *} \operatorname{Sig}<0.05$ and ${ }^{*} \operatorname{Sig}<0.10$; spatial weight matrix: threshold distance $900 \mathrm{~m}$.

TABLE 9: Parameters estimation using 20-minute study range, SAR, and 900-metre threshold distance.

\begin{tabular}{lccc}
\hline Indicators & Coef. & Std. Error & $t$ \\
\hline Shopping mall & $0.030^{* *}$ & 0.046 & 3.214 \\
Commercial street & $0.018^{* *}$ & 0.024 & 2.145 \\
Link & $0.021^{* *}$ & 0.031 & 2.547 \\
Construction area & $0.037^{* *}$ & 0.025 & 3.125 \\
Reputation & $0.132^{* *}$ & 0.033 & 2.101 \\
Parking space & $0.008^{* *}$ & 0.014 & 1.955 \\
Distance to metro station & & & \\
$\quad$ Range of 0-5 min & $0.193^{* *}$ & 0.030 & 1.588 \\
$\quad$ Range of 5-10 min & $0.188^{* *}$ & 0.039 & 2.021 \\
$\quad$ Range of 10-15 min & $0.141^{* *}$ & 0.021 & 3.612 \\
$\quad$ Range of 15-20 min & $0.108^{* *}$ & 0.014 & 1.301 \\
Inner wall area & $0.400^{* *}$ & 0.023 & 1.141 \\
Yanta-Qujiang area & $0.462^{* *}$ & 0.019 & 0.988 \\
Gaoxin business area & $0.015^{* *}$ & 0.025 & 3.214 \\
Bus line number & $0.024^{* *}$ & 0.037 & 2.574 \\
School & $0.015^{* *}$ & 0.015 & 2.199 \\
Hospital & $-0.108^{* *}$ & 0.031 & -1.245 \\
Passenger flow & $0.255^{* *}$ & 0.027 & 2.301 \\
$R^{2}$ & 0.401 & - & - \\
Akaike info criterion (AIC) & -383.941 & - & - \\
\hline
\end{tabular}

${ }^{* *} \operatorname{Sig}<0.05$ and ${ }^{*}$ Sig $<0.10$; spatial weight matrix: Threshold distance $900 \mathrm{~m}$.

not used in related studies of other cities [10-12, 22-24, 27]. "Passenger Flow" is shown to have a stronger impact than the "Distance to Metro station" indicator on the rental price, leading to a $25.5 \%$ price increase.

Although the focus is on indicators related to metro station, some of the other indicators appear to have a stronger impact on the commercial property value. The "Yanta-Qujiang Area" and "Inner Wall Area" indicators, which are related to the location of the commercial properties, rank the first (0.462) and second (0.400) in terms of impact on rental price, respectively. This is because the two regions have been the traditional commercial areas in Xi'an for over 15 years. Despite any inconveniences, local residents have developed a habit of shopping in these areas. In some studies of other cities, indicators irrelevant to urban rail transit have also been shown to have a stronger impact on the commercial property value. The most impactful indicator in San Diego [11], Minneapolis [12], Seoul [23], and 
Wuhan [27] was found to be the "Vacant Land," "Number of stories," "CBD zone," and "Zhongshan Business indicators," respectively.

Moreover, the study range is determined to be a 20minute walking time. Based on Xi'an 2019 Annual Travel Report [35], a walking speed of $5.0 \mathrm{~km} / \mathrm{h}$ is used in this study. Therefore, this distance range is $1.67 \mathrm{~km}$. This is a larger distance than $1.0 \mathrm{~km}$ in Shanghai case [21], $0.8 \mathrm{~km}$ in San Diego case [11], and $1.5 \mathrm{~km}$ in Dubai case [13]. Among these cases, Dubai case studied commercial properties, while Shanghai and San Diego studies focused on residential properties. Generally, the study ranges used in residential properties' research studies are lower than those on commercial properties. People are more accepting longer walking times when shopping or engaging in other entertainment activities than going back home. Besides, in commercial property related research studies, the study range varies in different cities. Among Xi'an, Wuhan [27], and Dubai [13], Wuhan has the shortest walking range. In our opinion, the topography of the city may explain this difference. Commercial properties can be more centralized in cities with flat terrain, such as Xi'an or Dubai, and larger subcenters could be built. However, the hilly terrain and the two rivers that cross the downtown of Wuhan forces smaller subcenters to be developed that are sparsely scattered. For instance, the Government Center, Inner Wall Area, Yanta-Qujiang Area, and Gaoxin Business Area in Xi'an have land areas of $2.4 \mathrm{~km}^{2}, 5.9 \mathrm{~km}^{2}, 11.5 \mathrm{~km}^{2}$, and $5.4 \mathrm{~km}^{2}$, respectively (https://www.amap.com/). The subcenters of Hanzheng Street Business District, Jianghan Road Business District, Hongshan Square Business District, and Guanggu Business District in Wuhan have land areas of $1.3 \mathrm{~km}^{2}$, $1.5 \mathrm{~km}^{2}, 0.7 \mathrm{~km}^{2}$, and $1.6 \mathrm{~km}^{2}$, respectively (https://www. amap.com/), which are much smaller than the subcenter land areas of Xi'an.

\section{Conclusions}

In this study, indicators affecting commercial property value in metro station accessible areas were investigated, using the Xi'an metro system as a case. As the roads are not straight in most cases, Euclidean distance could not always equal to actual distance the passenger travels from the metro station to a commercial spot, walking time consumption measuring the study range was used to fix this problem. Following the conceptual framework presented by Abutaleb et al. [14] and combining the existing empirical evidences $[12-14,21,25-27,35]$, the initial indicator set was built, and 422 commercial property samples were investigated. Using HPM for two times, 14 indicators were found to be significant, and multicollinearity in initial indicator set was not reported. Autocorrelation problem was solved by the weighted decision matrix tool with appropriate threshold distance equals to $900 \mathrm{~m}$. Based on the comparison among HPM, SEM, and SAR, SAR performed best of having the largest $R^{2}(0.415)$ and the lowest AIC (-395.214). By dividing the walking distances into 8 subranges, 20 min walking distance was chosen as the study range based on the significance analysis using SAR. Then, significant indicators affecting the commercial property value in metro station accessible areas are quantified using $20 \mathrm{~min}$ walking time consumption, SAR, and $900 \mathrm{~m}$ threshold distance.

\section{Contribution to Knowledge}

The results found in this study, including the range of $20 \mathrm{~min}$ walking time significant indicators, could provide some empirical evidences to commercial property planning in Xi'an. For instances, in constructing new metro lines in Xi'an, a commercial property wishes to obtain higher rental prices should locate inside this range (20 min walking time) away from the nearest metro station. Moreover, newly constructed metro stations in Yanta-Qujiang Area and Inner Wall Area have better potential in commercial property planning, due to the obviously higher significance of these two parameters in Table 9. As to other cities, the results obtained in Xi'an in Table 9 could not be used directly. However, the method of using walking time consumption to measure the study range is considered to be more appropriate compared to methods using Euclidean distance, which could be used in studies on the commercial property value in metro station accessible areas in other cities, to obtain more applicable results.

However, this study also has a limitation. This study is carried out in a single city, Xi'an, like most related studies mentioned in Section 2. Although the method of using walking time consumption to measure the study range has the potential to be deployed in other cities, the results obtained in this research are still limited in Xi'an. Therefore, more efforts should be made focusing on commercial property value in several cities, to obtain more transferable results, through an in-depth and comprehensive analysis.

\section{Data Availability}

The data used to support the findings of this study are available from the corresponding author upon request.

\section{Conflicts of Interest}

The authors declare that there are no conflicts of interest regarding the publication of this paper.

\section{Authors' Contributions}

Xingliang Liu and Zhen Cao conceptualized the study; Xingliang Liu, Zhen Cao, and Bin Lei worked on the methodology; Xingliang Liu, Zhen Cao, and Changjiang Liu carried out investigation; Xingliang Liu carried out writing, original draft preparation; Lizhu Jing carried out writing, review and editing.

\section{Acknowledgments}

This research was funded by Shaanxi Transportation Technology Project (16-40K) and partly supported by 
Science Foundation Project of Chongqing Jiaotong University (Grant no. 20JDKJC-B001).

\section{References}

[1] D. B. Hess and T. M. Almeida, "Impact of proximity to light rail rapid transit on station-area property values in buffalo, New York," Urban Studies, vol. 44, no. 5-6, pp. 1041-1068, 2007.

[2] J. A. Kilpatrick, R. L. Throupe, J. I. Carruthers, and A. Krause, "The impact of transit corridors on residential property values," Journal of Real Estate Research, vol. 29, no. 3, pp. 303-320, 2007.

[3] G. Giuliano, P. Gordon, Q. Qisheng Pan, and J. Park, "Accessibility and residential land values: some tests with new measures," Urban Studies, vol. 47, no. 14, pp. 3103-3130, 2010.

[4] A. Golub, S. Guhathakurta, and B. Sollapuram, "Spatial and temporal capitalization effects of light rail in phoenix," Journal of Planning Education and Research, vol. 32, no. 4, pp. 415-429, 2012.

[5] K. Seo, A. Golub, and M. Kuby, "Combined impacts of highways and light rail transit on residential property values: a spatial hedonic price model for Phoenix, Arizona," Journal of Transport Geography, vol. 41, pp. 53-62, 2014.

[6] C.-H. C. Bae, M.-J. Jun, and H. Park, "The impact of Seoul's subway Line 5 on residential property values," Transport Policy, vol. 10, no. 2, pp. 85-94, 2003.

[7] D. P. McMillen and J. McDonald, "Reaction of house prices to a new rapid transit line: Chicago's midway line, 1983-1999," Real Estate Economics, vol. 32, no. 3, pp. 463-486, 2004.

[8] Q. Pan, H. Pan, M. Zhang, and B. Zhong, "Effects of rail transit on residential property values," Transportation Research Record: Journal of the Transportation Research Board, vol. 2453, no. 1, pp. 118-127, 2014.

[9] G. M. Ahlfeldt, "If we build it, will they pay? Predicting property price effects of transport innovations," Environment and Planning A: Economy and Space, vol. 45, no. 8, pp. 1977-1994, 2013.

[10] A. C. Nelson, D. Eskic, and J. P. Ganning, "Retail rent with respect to distance from light transit stations in Dallas and Denver," in Proceedings of the 94th Annual Meeting of the Transportation Research Board, Washington, DC, USA, January 2015.

[11] R. Cervero, "Effects of light and commuter rail transit on land prices: experiences in San Diego County," Journal of the Transportation Research Forum, vol. 43, no. 1, pp. 121-138, 2004.

[12] K. Ko and X. Cao, "The impact of Hiawatha Light Rail on commercial and industrial property values in Minneapolis," Journal of Public Transportation, vol. 16, no. 1, pp. 47-66, 2013.

[13] S. I. Mohammad, D. J. Graham, and P. C. Melo, "The effect of the Dubai Metro on the value of residential and commercial properties," Journal of Transport and Land Use, vol. 10, no. 1, pp. $1-25,2017$.

[14] A. Abutaleb, K. McDougall, M. Basson, R. Hassan, and M. N. Mahmood, "Towards a conceptual framework for understanding the attractiveness of rail transit-oriented shopping mall developments (TOSMDs)," Urban Rail Transit, vol. 5, no. 4, pp. 225-239, 2019.

[15] K. Kim and M. L. Lahr, "The impact of Hudson-Bergen light rail on residential property appreciation," Papers in Regional Science, vol. 93, pp. S79-S97, 2014.
[16] J. Dubé, M. Thériault, and F. Des Rosiers, "Commuter rail accessibility and house values: the case of the Montreal South Shore, Canada, 1992-2009," Transportation Research Part A: Policy and Practice, vol. 54, pp. 49-66, 2013.

[17] J. Gadzinski and A. Radzimski, "The first rapid tram line in Poland: how has it affected travel behaviours, housing choices and satisfaction, and apartment prices?" Journal of Transport Geography, vol. 54, pp. 451-463, 2016.

[18] W. Sun, S. Zheng, and R. Wang, “The capitalization of subway access in home value: a repeat-rentals model with supply constraints in Beijing," Transportation Research Part A: Policy and Practice, vol. 80, pp. 104-115, 2015.

[19] F.-M. Liou, S.-Y. Yang, B. Chen, and W.-P. Hsieh, “The effects of mass rapid transit station on the house prices in Taipei: the hierarchical linear model of individual growth," Pacific Rim Property Research Journal, vol. 22, no. 1, pp. 3-16, 2016.

[20] H. Sun, Y. Wang, and Q. Li, “The impact of subway lines on residential property values in Tianjin: an empirical study based on hedonic pricing model," Discrete Dynamics in Nature and Society, vol. 2016, Article ID 1478413, 10 pages, 2016.

[21] C. Guan and R. Peiser, "Accessibility, urban form, and property value: a study of Pudong, Shanghai," Journal of Transport and Land Use, vol. 11, no. 1, pp. 1057-1080, 2018.

[22] R. Cervero and M. Duncan, "Transit's added value. At what point does locating near transit raise real estate values?" Urban Land, vol. 61, pp. 77-87, 2002.

[23] J. Kim and M. Zhang, "Determining transit's impact on Seoul commercial land values: an application of spatial econometrics," International Real Estate Review, vol. 8, no. 1, pp. 1-26, 2005.

[24] J. F. Pacheco-Raguz, "Assessing the impacts of light rail transit on urban land in Manila," Journal of Transport and Land Use, vol. 3, pp. 113-138, 2010.

[25] Li Han, W. D. Yehua, Y. Wu, and G. Tian, "Analyzing housing prices in Shanghai with open data: amenity, accessibility and urban structure," Cities, vol. 91, pp. 165-179, 2019.

[26] Z. Chen and K. E. Haynes, "Impact of high speed rail on housing values: an observation from the Beijing-Shanghai line," Journal of Transport Geography, vol. 43, pp. 91-100, 2015.

[27] T. Xu, M. Zhang, and P. T. Aditjandra, "The impact of urban rail transit on commercial property value: new evidence from Wuhan, China," Transportation Research Part A: Policy and Practice, vol. 91, pp. 223-235, 2016.

[28] G. Debrezion, E. Pels, and P. Rietveld, "The impact of railway stations on residential and commercial property value: a meta-analysis," The Journal of Real Estate Finance and Economics, vol. 35, no. 2, pp. 161-180, 2007.

[29] R. Trojanek and M. Gluszak, "Spatial and time effect of subway on property prices," Journal of Housing and the Built Environment, vol. 33, no. 2, pp. 359-384, 2018.

[30] S. Gibbons and S. Machin, "Valuing rail access using transport innovations," Journal of Urban Economics, vol. 57, no. 1, pp. 148-169, 2005.

[31] M. Diao, "Selectivity, spatial autocorrelation and the valuation of transit accessibility," Urban Studies, vol. 52, no. 1, pp. 159-177, 2014.

[32] J. P. Le Sage and R. K. Pace, Introduction to Spatial Econometrics, CRC Press, Boca Raton, FL, USA, 2009.

[33] J. P. Le Sage, "What regional scientists need to know about spatial econometrics," SSRN Electronic Journal, vol. 44, no. 1, 2014. 
[34] X. Cao and D. Porter-Nelson, "Real estate development in anticipation of the Green Line light rail transit in St. Paul," Transport Policy, vol. 51, pp. 24-32, 2016.

[35] AMAP, Traffic Analysis Report of Major Cities in China, AMAP, Tromsø, Norway, https://report.amap.com/index.do.

[36] L. Anselin, Spatial Econometrics: Methods and Models, Kluwer Academic Publishers, Dordrecht, Netherlands, 1988.

[37] C. Pasquale, K. S. Suna, and K. Ingrid, Complexity and Geographical Economics: Topics and Tools, Springer, Berlin, Germany, 2015.

[38] B. T. H. Yen, C. Mulley, H. Shearer, and M. Burke, "Announcement, construction or delivery: when does value uplift occur for residential properties? evidence from the gold coast light rail system in Australia," Land Use Policy, vol. 73, pp. 412-422, 2018.

[39] D. Efthymiou and C. Antoniou, "How do transport infrastructure and policies affect house prices and rents? Evidence from Athens, Greece," Transportation Research Part A: Policy and Practice, vol. 52, pp. 1-22, 2013.

[40] A. Can, "Specification and estimation of hedonic housing price models," Regional Science and Urban Economics, vol. 22, no. 3, pp. 433-452, 1992. 